\title{
Adiponectin response to supervised aerobic training in type II diabetic patients
}

\author{
Farag A. Aly ${ }^{\mathrm{a}, \mathrm{c}}$, Ahmad H. Alghadir ${ }^{\mathrm{a}}$, Sami A. Gabr ${ }^{\mathrm{a}, \mathrm{b}}$ \\ ${ }^{a}$ Rehabilitation Research Chair, Department of Rehabilitation Sciences, College of Applied Medical \\ Sciences, King Saud University, Riyadh, Saudi Arabia, ${ }^{b}$ Department of Anatomy, Faculty of Medicine, \\ Mansoura University, Mansoura City, Egypt, 'Faculty of Physical Therapy, Cairo University, Giza, \\ Egypt
}

\begin{abstract}
Background: Cross-sectional studies have linked decreased adiponectin levels with several metabolic traits, including insulin resistance, dyslipidemia, and metabolic syndrome. Previous studies conducted to investigate the effects of acute or chronic exercise on the serum adiponectin have produced conflicting and controversial results.

Objective: To investigate the effect of supervised aerobic training of moderate intensity on the total serum levels of adiponectin and its relationship to insulin resistance and body weight in subjects with type 2 diabetes (DM2).

Methods: Thirty-five patient participants diagnosed as having DM2 mellitus for more than 5 years with normal or near normal body weight took part in this study. The diagnosis of DM was based on the American Diabetes Association criteria for type 2 diabetes mellitus. Serum levels of blood glucose, insulin, total adiponectin, high molecular weight adiponectin, and insulin resistance were determined before and after a 12-week program of supervised moderate intensity aerobic training.

Results: Twelve weeks of supervised moderate intensity aerobic training produced a significant reduction of fasting blood sugar, fasting insulin, glycosylated hemoglobin, and insulin resistance in male subjects with DM2. By contrast, a significant increase in the total serum adiponectin and high molecular weight adiponectin has been reported. There was no significant correlation between the reduction of the body mass index, insulin resistance, and the increase of the total serum adiponectin or high molecular weight adiponectin.

Conclusion: Prolonged exercise training of at least moderate intensity improves levels of adiponectin and insulin sensitivity in men with type 2 diabetes.
\end{abstract}

Keywords: Adiponectin, aerobic training, type 2 diabetes

Adiponectin is a hormone secreted from adipocytes, which is proposed to play a key role in metabolism [1-3]. Cross-sectional studies link decreased adiponectin levels with several metabolic traits, including insulin resistance, dyslipidemia, and the metabolic syndrome [2, 4, 5]. Moreover, low levels of adiponectin predict future development of diabetes [6], cardiovascular disease [7] and obesity-associated malignancies [8, 9].

Several multimeric forms of adiponectin circulate in serum, and these various forms are postulated to have differing biologic activity [10, 11]. High-

Correspondence to: Dr. Sami A. Gabr, Rehabilitation Research Chair, King Saud University, Riyadh 12372, Saudi Arabia. E-mail: nadalab2009@hotmail.com,drgabr14@yahoo.com, sgabr@ksu.edu.sa molecular weight (HMW) adiponectin is proposed to be the biologically active form of the hormone, and, therefore, it has been proposed that HMW adiponectin may predict metabolic parameters better than total adiponectin [12]. This is in addition to direct and indirect functions related to endothelial cells because HMW adiponectin promotes insulin sensitivity and inhibits inflammatory mediators [13]. Full-length HMW adiponectin assists insulin to inhibit glucose production by the liver, while the globular domain of the adiponectin protein promotes fatty acid oxidation in skeletal muscles and other tissues in both animals and humans [14].

Previous studies conducted to investigate the effects of acute or chronic exercise on the serum adiponectin produced conflicting and controversial findings. Some of those studies found that the 
adiponectin level in blood is not affected by acute exercise in healthy, normal weight subjects [15-17]. By contrast, adiponectin levels were found significantly decreased immediately after exercise and increased $30 \mathrm{~min}$ after exercise in other healthy subjects with normal weight [18]. While a short period of exercise training for one week increased adiponectin levels and insulin sensitivity in obese subjects without weight loss [19].

Some investigators concluded that acute and chronic exercise do not affect adiponectin levels in lean and healthy subjects [20], and 8 weeks of intensive training that reduced abdominal fat and increased insulin sensitivity had no effect on adiponectin in diabetic men [21]. On the other hand, aerobic exercise training for two to three times per week in the presence of weight loss increased adiponectin levels and insulin sensitivity at week 16 in obese subjects with moderate dyslipidemia [22]. To clarify the effect of exercise on adiponectin levels, we sought to investigate the effect of supervised aerobic training of moderate intensity on the serum levels of total and HMW adiponectin and its relationship to insulin resistance and body weight in patients with type 2 diabetes.

\section{Materials and methods Subjects}

Thirty-five men diagnosed with type 2 diabetes mellitus (DM2) for more than 5 years with normal or near normal body weight participated in this study. The diagnosis of DM2 was based on the American Diabetes Association criteria (fasting plasma glucose level higher than $126 \mathrm{mg} / \mathrm{dL}$ and/or a glucose level exceeding $200 \mathrm{mg} / \mathrm{dL}$ at 2 hours in a $75 \mathrm{~g}$ oral glucose tolerance test) [23]. General characteristics of the participants are shown in Table 1. All were nonsmokers and had no history of abnormal alcohol intake. Standardized measurements of weight and height were taken in light clothing without shoes. Standardized physical examination, and collection of serum samples were performed at week 0 (before onset of the training program), and after a 12-week program of moderate aerobic training. All subjects were requested to consume no alcohol and not to participate in other recreational activities (including other exercise programs) during the study period. Exclusion criteria included a body mass index (BMI) of more than $30\left(\mathrm{~kg} / \mathrm{m}^{2}\right)$, type 1 diabetes, smokers, anemia, overt complications of diabetes like nephropathy, neuropathy, retinopathy, obvious ischemic heart disease (angina, myocardial infarction, and lead electrocardiogram abnormalities), HCV, HBV, chronic liver disease, hypothyroidism, and drugs (diuretics; oral contraceptives). This study was approved by the ethics committee of the Rehabilitation Research Chair (RRC), King Saud University, KSA, under file number (ID: RRC-2013-010). All participants completed and signed an informed consent form before starting the study.

\section{Procedures}

Blood sampling and analysis

Blood samples were obtained from all subjects at $0800 \mathrm{~h}$ after an overnight fast before and after the training program. Venous blood samples $(5 \mathrm{~mL})$ were collected into plain tubes, the samples were allowed to clot for half an hour following which samples were centrifuged for 15 minutes at $2000 \mathrm{rpm}$. Samples were given a coded study identiûcation number and were stored frozen at $80^{\circ} \mathrm{C}$ until analysis.

A) Analysis of blood sugar and glycated hemoglobin (HbA1c). Blood glucose was measured using a glucose oxidase and peroxidase (GOD-POD) colorimetric method (Quanti Chrom Glucose Assay Kit, DIGL-100, BioAssay Systems, Hayward, CA, USA). HbA1c was measured using a commercial kit (Bio-Rad, Richmond, CA, USA), normal range from 3.5 to $5.5 \%$ (coefficient of variation $5 \%$ ). The assays were performed according to the instructions provided by the manufacturers.

Table 1. General characteristics of the subjects

\begin{tabular}{llllc}
\hline & Age (years) & Weight $(\mathbf{k g})$ & Height $(\mathbf{c m})$ & Body mass index $(\mathbf{B M I})\left(\mathbf{k g} / \mathbf{m}^{2}\right)$ \\
\hline Male $(\mathrm{n}=35)$ & $43.3 \pm 8.9$ & $76.6 \pm 6.0$ & $171.8 \pm 6.4$ & $26 \pm 2.2$ \\
\hline
\end{tabular}


B) Analysis of insulin and insulin resistance (IR). Serum insulin level was determined using an ELISA (human insulin ELISA kit, KAQ1251, Invitrogen Corporation, Camarillo, CA,USA). Insulin resistance in fasting state was determined using a homeostasis model assessment (HOMA-IR) and was calculated from fasting insulin (IF) and fasting glucose (GF) as follows: HOMA-IRZ(IF!GF)/22.5 [24]. The units for IF were $\mathrm{mU} / \mathrm{ml}$ and for GF mmol/l. The validity and reliability of HOMA-IR have been ascertained in previous studies that have demonstrated a high correlation between HOMA-IR and the glucose clamp technique not only before, but also after, treatment in type 2 diabetic patients [25, 26].

C) Adiponectin assays. Serum levels of total adiponectin and HMW Adiponectin, were determined using a novel ELISA(ADIPOA; ALPCO Diagnostics, Salem, NH, USA). The sensitivity of this assay is $0.04 \mathrm{ng} / \mathrm{ml}$. The recovery rate was $99 \%-103 \%$ for total adiponectin and $97 \%-105 \%$ for HMW adiponectin. The effect of serial dilutions has been tested on human serum samples, and linearity and specificity of the assay has been documented [27]. All samples, before and after exercise, were measured together in the same assay according to the instructions provided by the manufacturer.

\section{Exercise training program}

Each participant underwent the exercise training program three times per week for 12 weeks. The program was designed in the form of a treadmill walking mode. Each participant's training intensity was calculated as training heart rate (THR) based on his age predicted maximum heart rate and resting heart rate obtained according to Karvonen's formula [28] $($ THR $=$ HRrest $+($ HRmax - HRrest $) \times$ TF, where HRrest $=$ resting heart rate in bpm. HRmax = maximum heart rate in bpm. $\mathrm{TF}=$ training fraction; was from $65 \%$ to $75 \%$ for moderate intensity used in this study. Each exercise session consisted of three phases, that is, warm-up, active, and cool-down phases. During the warm-up phase, the subject performed a simple stretching exercise for all large muscle groups and walked for 5 to 10 minutes at a TF equal to $30 \%-40 \%$. During the active phase, the subject was allowed to reach his precalculated training heart rate (THR) in bouts with a total time of from 30 to 45 minutes. The last phase was cool-down, which continued for 10 to 15 minutes where the workload decreased gradually until the participant's HR and blood pressure returned nearly to resting level. Throughout the entire training session, the heart rate of the participant was monitored using portable heart rate monitor to maintain exercise intensity within the precalculated training heart rate.

\section{Results}

Data are expressed as mean and standard deviation, and were analyzed by using SPSS software, version 10.0 (SPSS Inc, Chicago, IL, USA). A onetailed paired $t$ test was used to compare the pre- and the posttraining mean values of BMI, fasting blood sugar and insulin, glycosylated hemoglobin, insulin resistance, serum total adiponectin and HMW adiponectin. $P<0.05$ was used to determine significant differences. The results showed that 12 weeks of moderate aerobic training produced a significant reduction of fasting blood sugar, fasting insulin, glycosylated hemoglobin, and insulin resistance in the participants $(P<0.005)$. The total serum adiponectin and the HMW adiponectin had significantly increased by 12 weeks of moderate aerobic training $(<0.005)$ as shown in Table 2. There was no significant correlation between the reduction of the $\mathrm{BMI}$ or insulin resistance, and the increase of the total serum adiponectin or HMW adiponectin.

Table 2. Mean, standard deviation (SD) and statistical comparison of the pre training and the post training values of the studied variables $(n=35)$.

\begin{tabular}{lccrc}
\hline Variables & Pretraining values & Posttraining values & Mean difference & $\boldsymbol{P}$ \\
\hline Fasting blood sugar & $197 \pm 92.8$ & $146.3 \pm 21$ & $50.7 \pm 15$ & $<0.005$ \\
Glycosylated hemoglobin & $7.7 \pm 0.8$ & $6.3 \pm 0.6$ & $1.40 \pm 0.4$ & $<0.005$ \\
Fasting insulin & $40.6 \pm 9.3$ & $25.7 \pm 6.8$ & $14.9 \pm 3.5$ & $<0.005$ \\
Insulin resistance & $5.9 \pm 1.4$ & $3.6 \pm 0.9$ & $2.3 \pm 0.6$ & $<0.005$ \\
Serum adiponectin & $9.5 \pm 1.3$ & $38.5 \pm 5.8$ & $28.9 \pm 6.3$ & $<0.005$ \\
High molecular weight adiponectin & $5.3 \pm 1.4$ & $27.1 \pm 4.9$ & $21.7 \pm 4.8$ & $<0.005$ \\
Body mass index $\left(\mathrm{kg}^{2} \mathrm{~m}^{2}\right)$ & $26 \pm 2.2$ & $22.6 \pm 1.8$ & $3.8 \pm 1.6$ & $<0.005$ \\
\hline
\end{tabular}




\section{Discussion}

There has been much interest in serum adiponectin because of the observation that obese subjects and patients with type 2 diabetes have low serum adiponectin levels [29,30]. Reduction of body weight by diet intervention [31] and medical treatment [32] are given to improve insulin sensitivity and also produce elevated serum levels of adiponectin. Exercise training can improve insulin resistance [33, 34], but the effect of exercise training on plasma adiponectin and HMW adiponectin has remained controversial. Therefore, this present study sought to investigate the effects of moderate intensity aerobic exercise training for 12 weeks on serum adiponectin and HMW adiponectin and its relationship to reduction of body weight and improvements of insulin sensitivity among type 2 diabetic patients. We showed a significant increase of the total serum adiponectin and HMW adiponectin after 12 weeks of moderate aerobic training combined with a significant reduction of fasting blood sugar, fasting insulin, glycosylated hemoglobin, and insulin resistance, with no significant relationship between the reduction of the BMI or insulin resistance, and the increase of total serum adiponectin or HMW adiponectin. Our findings are in accordance with those of some previous studies that reported that even one week of exercise training increased adiponectin levels and insulin sensitivity in obese subjects without weight loss [19], and aerobic exercise training two to three times per week in the presence of weight loss had increased the adiponectin levels and insulin sensitivity at week 16 in obese subjects with moderate dyslipidemia [22]. By contrast, our finding are inconsistent with other studies that found that acute and chronic exercise does not affect adiponectin levels in lean and healthy subjects after 20 and 8 weeks of intensive training that reduced abdominal fat and increased insulin sensitivity, but had no effect on adiponectin in diabetic men [21]. This inconsistency between the results of this study and the previous studies may be in part related to the subjects who participated in the other studies, and whether they were diabetic or nondiabetic or to the intensity and duration of exercise training and the baseline values of insulin resistance and BMI. The increased total adiponectin and HMW adiponectin seen in this study could be interpreted by the significant reduction of body weight in the participating patients at the end of the 12 weeks of moderate aerobic training because it has been found that the adiponectin did not increased significantly after two weeks of training without reduction of body weight, but after 16 weeks of training adiponectin levels had a significantly reduced association with a significant reduction in body weight [22].

In this study 12 weeks of moderate aerobic training increased insulin sensitivity, which could be interpreted as increasing postreceptor insulin signaling [35] or by increased level of glucose transporter protein and mRNA [36], activating glycogen synthesis and hexokinase [37], or by increasing muscle glucose delivery and changes in muscle composition [38]. The improvement of insulin resistance noted in this study could be also related to the improvement of the adiponectin levels as previously reported [39, 40], but in this study we were unable to find significant correlation between the insulin sensitivity and the HMW of total adiponectin. Therefore, further studies are recommended to investigate other factors that may explain mechanisms behind increasing the adiponectin by prolonged supervised exercise training.

\section{Acknowledgements}

This project was supported by King Saud University, Deanship of Scientific Research, Rehabilitation Research Chair. The authors report no conflicts of interest to declare.

\section{References}

1. Berg AH, Combs TP, Du X, Brownlee M, Scherer PE. The adipocyte-secreted protein Acrp30 enhances hepatic insulin action. Nat Med. 2001; 7:947-53.

2. Weyer C, Funahashi T, Tanaka S, Hotta K, Matsuzawa Y, Pratley RE, et al. Hypoadiponectinemia in obesity and type 2 diabetes: close association with insulin resistance and hyperinsulinemia. J Clin Endocrinol Metab. 2001; 86:1930-5.

3. Hotta K, Funahashi T, Arita Y, Takahashi M, Matsuda M, Okamoto Y, I, et al. Plasma concentrations of a novel, adipose-specific protein, adiponectin, in type 2 diabetic patients. Arterioscler Thromb Vasc Biol. 2000; 20:1595-9.

4. Salmenniemi U, Ruotsalainen E, Pihlajamäki J, Vauhkonen I, Kainulainen S, Punnonen K, et al. Multiple abnormalities in glucose and energy metabolism and coordinated changes in levels of adiponectin, cytokines, and adhesion molecules in subjects with metabolic syndrome. Circulation. 2004; 110:3842-8.

5. Blüher M, Bullen JW Jr, Lee JH, Kralisch S, 
Fasshauer M, Kloting N, et al. Circulating adiponectin and expression of adiponectin receptors in human skeletal muscle: associations with metabolic parameters and insulin resistance and regulation by physical training. J Clin Endocrinol Metab. 2006; 91: 2310-6.

6. Lindsay RS, Funahashi T, Hanson RL, Matsuzawa Y, Tanaka S, Tataranni PA, et al. Adiponectin and development of type 2 diabetes in the Pima Indian population. Lancet. 2002; 360:57-8.

7. Schulze MB, Shai I, Rimm EB, Li T, Rifai N, Hu FB. Adiponectin and future coronary heart disease events among men with type 2 diabetes. Diabetes. 2005; 54:534-9.

8. Wei EK, Giovannucci E, Fuchs CS, WillettWC, Mantzoros CS. Low plasma adiponectin levels and risk of colorectal cancer in men: a prospective study. J Natl Cancer Inst. 2005; 97:1688-94.

9. Luhn P, Dallal CM, Weiss JM, Black A, Huang WY, Lacey JV Jr, et al. Circulating adiponectin and endometrial cancer risk. J Clin Endocrinol Metab. 2004; 89:1160-3.

10. Waki H, Yamauchi T, Kamon J, Ito Y, Uchida S, Kita S, et al. Impaired multimerization of human adiponectin mutants associated with diabetes: molecular structure and multimer formation of adiponectin. J Biol Chem. 2003; 278:40352-63.

11. Wang Y, Lam KS, Chan L, Chan KW, Lam JB, Lam MC, et al. Posttranslational modifications on the four conserved lysine residues within the collagenous domain of adiponectin are required for the formation of its high-molecular-weight oligomeric complex. J Biol Chem. 2006; 281:16391-400.

12. Hara K, Horikoshi M, Yamauchi T, Yago H, Miyazaki $\mathrm{O}$, Ebinuma H, et al. Measurement of the high molecular weight form of adiponectin in plasma is useful for the prediction of insulin resistance and metabolic syndrome. Diabetes Care. 2006; 29:1357-62.

13. Berg AH, Scherer PE. Adipose tissue, inflammation, and cardiovascular disease. Circ Res. 2005; 96:939-49.

14. Onay-Besikci A, Altarejos JY, Lopaschuk GD. gAdglobular head domain of adiponectin increases fatty acid oxidation in newborn rabbit hearts. J Biol Chem. 2004; 279:44320-6.

15. Ferguson MA, White LJ, McCoy S, Kim HW, Petty T, Wilsey J. Plasma adiponectin response to acute exercise in healthy subjects. Eur J Appl Physiol. 2004; 91:324-9.

16. Kraemer RR, Aboudehen KS, Carruth AK, Durand RT, Acevedo EO, Hebert EP, et al. Adiponectin responses to continuous and progressively intense intermittent exercise. Med Sci Sports Exerc. 2003; 35:1320-5.

17. Punyadeera C, Zorenc AH, Koopman R, McAinch AJ, Smit E, Manders R, et al. The effects of exercise and adipose tissue lipolysis on plasma adiponectin concentration and adiponectin receptor expression in human skeletal muscle. Eur J Endocrinol. 2005; 152: 427-36.

18. Jurimae J, Purge P, Jurimae T. Adiponectin is altered after maximal exercise in highly trained male rowers. Eur J Appl Physiol. 2005; 93:502-5.

19. Kriketos AD, Gan SK, Poynten AM, Furler SM, Chisholm DJ, Campbell LV. Exercise increases adiponectin levels and insulin sensitivity in humans. Diabetes Care. 2004; 27:629-30.

20. Bobbert T, Wegewitz U, Brechtel L, Freudenberg M, Mai K, Möhlig M, et al. Adiponectin oligomers in human serum during acute and chronic exercise: relation to lipid metabolism and insulin sensitivity. Int J Sports Med. 2007; 28:1-8.

21. Boudou P, Sobngwi E, Mauvais-Jarvis F, Vexiau P, Gautier JF. Absence of exercise-induced variations in adiponectin levels despite decreased abdominal adiposity and improved insulin sensitivity in type 2 diabetic men. Eur J Endocrinol. 2003; 149:421-4.

22. Yoshida H, Ishikawa T, Suto M, Kurosawa H, Hirowatari Y, Ito K, et al. Effects of supervised aerobic exercise training on serum adiponectin and parameters of lipid and glucose metabolism in subjects with moderate dyslipidemia. J Atheroscler Thromb. 2010; 17:1160-6.

23. American Diabetes Association. Standards of medical care in diabetes. Diabetes Care. 2009; 32:S13-61.

24. Matthews DR, Hosker JP, Rudenski AS, Naylor BA, Treacher DF, Turner RC. Homeostasis model assessment: insulin resistance and beta-cell function from fasting plasma glucose and insulin concentrations in man. Diabetologia. 1985; 28:412-9.

25. Okita K, Iwahashi H, Kozawa J, Okauchi Y, Funahashi T, Imagawa A, et al. Homeostasis model assessment as a clinical index of insulin resistance in type 2 diabetic patients treated with sulfonylureas. Diabetes Care. 1999; 22:818-22.

26. Katsuki A, Sumida Y, Gabazza EC, Murashima S, Furuta M, Araki-Sasaki R, et al. Homeostasis model assessment is a reliable indicator of insulin resistance during follow-up of patients with type 2 diabetes. Diabetes Care. 2001; 24:362-5.

27. Ebinuma H, Miyazaki O, Yago H, Hara K, Yamauchi T, Kadowaki T. A novel ELISA system for selective 
measurement of human adiponectin multimers by using proteases. Clin Chim Acta. 2006; 372:47-53.

28. Karvonen M, Kentala K, Mustala O. The effects of training heart rate: a longitudinal study. Ann Med Exp Biol Fenn. 1957; 35:307-15.

29. Hu E, Liang P, Spiegelman BM. Adipo Q is a novel adipose-specific gene dysregulated in obesity. J Biol Chem. 1996; 271:10697-703.

30. Hotta K, Funahashi T, Arita Y, Takahashi M, Matsuda M, Okamoto Y, et al. Plasma concentrations of a novel, adipose-specific protein, adiponectin, in type 2 diabetic patients. Arter Throm Vasc Biol. 2000; 20:1595-9.

31. Yang WS, Lee WJ, Funahashi T, Tanaka S, Matsuzawa Y, Chao CL, et al. Weight reduction increases plasma levels of an adipose-derived anti-inflammatory protein, adiponectin. J Clin Endo Metab. 2001; 86: 3815-9.

32. Phillips SA, Ciaraldi TP, Kong AP, Bandukwala R, Aroda V, Carter L, et al. Modulation of circulating and adipose tissue adiponectin levels by antidiabetic therapy. Diabetes. 2003; 52:667-74.

33. Goodyear LJ, Kahn BB. Exercise, glucose transport, and insulin sensitivity. Ann Rev Med. 1998; 49: 235-61.

34. Sajad A, Amir HH, Mohammad R H. Effects of resistance versus endurance training on serum adiponectin and insulin resistance index. Eur J Endocrinol. 2007; 157:625-31.
35. Dela F, Handberg A, Mikines KJ, Vinten J, Galbo H. GLUT4 and insulin receptor binding and kinase activity in trained human muscle. J Physiol. 1993; 469: 615-24.

36. Dela F ${ }^{1}$, Ploug T, Handberg A, Petersen LN, Larsen JJ, Mikines KJ, et al. Physical training increases muscle GLUT4 protein and mRNA in patients with NIDDM. Diabetes. 1994; 43:862-5.

37. Oberbach A, Tonjes A, Kloting N, Fasshauer M, Kratzsch J, Busse MW, et al. Effect of a 4 week physical training program on plasma concentrations of inflammatory markers in patients with abnormal glucose tolerance. Eur J Endocrinol. 2006; 154:577-85.

38. Klimcakova E, Polak J, Moro C, Hejnova J, Majercik $\mathrm{M}$, Viguerie $\mathrm{N}$, et al. Dynamic strength training improves insulin sensitivity without altering plasma levels and gene expression of adipokines in subcutaneous adipose tissue in obese men. J Clin Endocrinol Metab. 2006; 91:5107-12.

39. Waki H, Yamauchi T, Kamon J, Ito Y, Uchida S, Kita S, et al. Impaired multimerization of human adiponectin mutants associated with diabetes: molecular structure and multimer formation of Adiponectin. J Biol Chem. 2003; 278:40352-63.

40. Kadowaki T, Yamauchi T, Kubota N, Hara K, Ueki K, Tobe K. Adiponectin and adiponectin receptors in insulin resistance, diabetes, and metabolic syndrome. J Clin Invest. 2006; 116:1784-92. 